https://doi.org/10.32735/S0718-2201202100053951

209-229

\title{
EL PENSAMIENTO Y LA ESCRITURA DE CARLOS HUAYQUIÑIR RAIN: UNA LLAMADO POR LA EDUCACIÓN Y UN COMBATE CONTRA EL RACISMO
}

Carlos Huayquiñir Rain's Thought and Writing: A Call for Education and a Combat Against Racism

ENRIQUE ANTILEO BAEZA

Centro de Estudios Culturales Latinoamericanos

Universidad de Chile (Chile)

enriqueantileo@gmail.com

Resumen

Este artículo es resultado de una investigación exploratoria acerca del pensamiento y la escritura de Carlos Huayquiñir Rain (1913-1978), periodista autodidacta que escribió respecto del pueblo mapuche entre la década de 1930 y 1960. Tiene como propósito analizar dos tópicos centrales que emergen de la prosa de Huayquiñir dispuesta en la prensa mapuche de los años referidos. Por un lado, el llamado a la instrucción y la educación de la niñez y la juventud mapuche realizado por el autor; por otro, su lucha contra el racismo manifiesto en la prensa, los políticos y las instituciones escolares. El artículo nace de una investigación realizada en la Hemeroteca de la Biblioteca Nacional de Chile, más el trabajo en archivos privados y espera contribuir al conocimiento refrente a este autor mapuche.

Palabras clave: Pueblo mapuche; Carlos Huayquiñir; diarios mapuches; educación; racismo.

\section{Abstract}

This article is the result of an exploratory research on the thinking and writing of Carlos Huayquiñir Rain (1913-1978), a self-taught journalist who wrote about the Mapuche people between the 1930s and 1960s. Its purpose is to analyze two central topics that emerge of the prose of Huayquinir arranged in the Mapuche press of the referred years. On the one hand, the call for instruction and education for mapuche children made by the author; on the other, his fight against racism manifested in the press, politicians and school institutions. The article stems from an investigation carried out in the Hemeroteca of the National Library of Chile, plus the work in private archives. It hopes to contribute to the knowledge about this Mapuche author.

Key words: Mapuche people; Carlos Huayquiñir; mapuche press; education; racism.

\section{INTRODUCCIÓN}

Carlos Huayquiñir Rain (1913-1978), fue un periodista autodidacta que emergió en el universo de las letras mapuches a fines de la década de 1930. Escribió inicialmente en el periódico El Frente Araucano, para luego desplegar sus textos en el Heraldo Araucano, ambos producidos en el seno del movimiento mapuche. Más adelante será el 
director del periódico Acción Araucana en la década de los cincuenta y autor de la revista Arauco de ayer y de hoy publicada en 1966.

Huayquiñir también fue un activo militante de las primeras organizaciones mapuches que surgieron en Santiago. Participó desde los comienzos de la Sociedad de Araucanos Galvarino, nacida en 1932 y de otras agrupaciones que dieron vida al movimiento mapuche capitalino como la Alianza Cultural Araucana o la Corporación Lautarina. Los periódicos que dirigió y donde escribió fueron sobre todo órganos de difusión de las sociedades que los formaron y financiaron.

La obra de Carlos Huayquiñir en gran medida es desconocida. Muy pocas veces ha sido mencionado en las investigaciones dedicadas al pueblo mapuche. José Bengoa y Eduardo Valenzuela hacen una referencia en su libro Economía Mapuche (1984, pp.103107). También Rolf Foerster y Sonia Montecino, en el clásico Organizaciones, líderes y contiendas mapuche (1900-1970), también aluden a la revista Arauco de ayer y de hoy, hasta ahora el trabajo más conocido del autor (1988, p.155). En este contexto, considero necesario revisar algunas de las escrituras de Huayquiñir y visibilizar una selección de las temáticas que aborda en sus textos.

En ese sentido, el presente artículo es resultado de una investigación exploratoria respecto del quehacer intelectual del autor referido y tiene como propósito analizar el pensamiento de Carlos Huayquiñir Rain a partir de sus publicaciones en periódicos entre 1939 y 1966, enfatizando al menos dos nudos críticos que afloran en sus letras. Por un lado, el lugar de la educación en el contexto mapuche de la década del cuarenta; por otro, la reflexión pertinente al racismo que despliega en varios de sus documentos, enfatizando en las formas en que se manifiesta en la política chilena, la prensa y las instituciones escolares.

Desde lo metodológico, esta investigación se basa en la recopilación de prensa mapuche realizada en la Hemeroteca de la Biblioteca Nacional de Santiago y en archivos privados, efectuada durante el 2019 y parte del 2020. De este ejercicio, se ha construido un corpus textual de publicaciones que vieron lugar en los diarios El Frente Araucano, Heraldo Araucano y Acción Araucana, y además en revista Arauco de ayer y de hoy del autor, hasta el momento el texto más citado en la bibliografía especializada acerca del pueblo mapuche. A partir de este material recopilado, se han ordenado y sistematizado algunos de los grandes tópicos a los que hizo referencia Huayquiñir mientras escribió. Asimismo, se ha podido comparar las ideas de Carlos Huayquiñir con otros pensadores y pensadoras mapuches de su época, lo que también aporta a un mejor acercamiento a su trabajo y sus contextos de producción.

La presentación que sigue se despliega abordando, en primer lugar, el escenario histórico en que se desarrolló la escritura de Huayquiñir, las organizaciones en las que participó, los lineamientos políticos a los que adhirió y sus diferencias con otros referentes organizacionales mapuches entre los años treinta y sesenta. Luego, en segundo lugar, enfatiza la cuestión de la educación y el pueblo mapuche como un anclaje relevante en el 210 | AlPHA № 53 (DicIEMBre 2021) PÁGS. 209-229. ISSN 07 16-4254 
pensamiento de Huayquiñir como en sus contemporáneos. Por último, se analiza la preocupación del autor frente al racismo y las formas de respuestas que encuentra su generación en este escenario. El artículo concluye dejando entrever la relevancia de abrir otras rutas de investigación para la visibilización de autorías poco conocidas como las de Carlos Huayquiñir y de tantas otras y otros pensadores de este tiempo.

\section{CONTEXTO HISTÓRICO MAPUCHE, PARTICIPACIÓN POLÍTICA Y POSICIONAMIENTOS}

Durante la década de 1920, varios migrantes mapuches en Santiago de Chile, provenientes de diversas reducciones, dan vida a las que parecieran ser las primeras organizaciones mapuches nacidas en la capital. Una reseña escrita por Norberto Pichilaf en 1953, al cumplirse el vigésimoprimer aniversario de la Sociedad Galvarino, relata primero el surgimiento de la Sociedad Pro Defensa de la Raza en 1927, organización que no logró funcionar, pero que dejó plasmado el interés por constituir una mutual entre los mapuches de la capital. Desde esta Sociedad y desde la convicción de forjar una institución que velase por los intereses del pueblo, una veintena de jóvenes mapuches se reagruparán en la conocida Galvarino durante el convulsionado $1932^{1}$.

En la misma reseña de Pichilaf se detalla que el directorio inicial de esta estuvo conformado por Arturo Huenchullán como presidente, Pablo Huichalaf como vicepresidente, Francisco Painemal como secretario, Ernesto Painequeo como prosecretario, Martín Painemal como tesorero, Norberto Pichilaf como protesorero y como directores: Antonio Melillán, Juan de Dios Huenupil, Ramón Huenchún, Jerónimo Levío y Pascual Treumún. Desde ese momento en adelante la organización irá creciendo y manteniendo una vida política muy activa que irrumpe en el contexto santiaguino. El escenario general de la movilización mapuche repercutirá en sus alianzas, sobre todo con el Frente Único Araucano de La Araucanía. La asociación trabajará en varios frentes, entre ellos promocionará un club deportivo e inaugurará un periódico como órgano de difusión.

En la organización convergían obreros mapuches avecindados en el centro de Santiago y algunos estudiantes. En medio de la pobreza urbana confinada en los cité (De Ramón, 1990), aparecía una expresión mancomunada que buscaba un espacio de encuentro entre mapuches. Un afán mutual motivaba la misión de la agrupación: el ayudarse entre hermanos del mismo pueblo ante las dificultades que significaban el arribo a la ciudad y la búsqueda de trabajo. Asimismo, estos jóvenes promovían la dignificación y el orgullo de ser mapuche entre sus "compatriotas".

La década de 1930 es clave para entender cómo se articula el movimiento mapuche en la ciudad de Santiago. Lejos de las reducciones, pero profundamente vinculados con las familias y agrupaciones mapuches del sur y sus agendas políticas, la

\footnotetext{
${ }^{1}$ La Cultura, año I, número 1, pp. 3-9, diciembre de 1953. Santiago de Chile.
} 
Sociedad Galvarino será una de las primeras orgánicas de aquella ciudad capital que comenzaba a expandir su radio urbano. A la Galvarino se sumarán en los años venideros, organizaciones de tranviarios, de profesores y clubes deportivos.

En cuanto a las afinidades políticas, la Sociedad Galvarino fue muy cercana al Frente Único Araucano. Esta última organización -fundada en 1939 luego del Congreso Nacional Araucano realizado en abril de aquel año en la Casa América de la ciudad de Temuco-, surgió de la participación de varias agrupaciones, entre ellas: Los Hijos de Arauco, Moderna Araucanía, Colonia Agrícola Araucana, Alianza Femenina Araucana, Sociedad Fresia, Sociedad Araucana Femenina Tegualda, Cooperativa Agrícola Araucana. La Sociedad Galvarino, por cierto, estuvo entre los referentes con mayor expresión en este Congreso, siendo nombrado Norberto Pichilaf como parte de la dirección y contando con una importante participación de otros miembros como Alberto Melillán y Teodoberto Neculmán (Foerster y Montecino, 1988, pp. 155-156).

Esta generación de nuevos dirigentes, como Carlos y Andrés Chihuailaf, Gregorio Seguel, Luis Segundo Marrián, Andrés Huichalaf, Lucía Catrileo, comenzaba a disputar un lugar en la política mapuche. Hasta este momento, organizaciones como Sociedad Caupolicán, la Federación Araucana y la naciente Corporación Araucana, que reunía a varios dirigentes de renombre, tenían mayor hegemonía en el espacio público, así como lo han demostrado diversos estudios (Marimán, 2007b; Menard, 2013; Vergara, Foerster y Gundermann, 2005). En ese contexto, esta camada de jóvenes intentará aparecer e incidir con una agenda relacionada con la situación territorial, la cuestión de los créditos indígenas y propuestas en el plano educativo.

Inmiscuida en este escenario de alianzas entre las dirigencias del sur y Santiago, la Sociedad Galvarino tomó la determinación de lanzar un periódico para difundir las ideas institucionales y mantener informada a la población mapuche de Santiago. Bajo el nombre de El Frente Araucano, su primer número salió a la luz en julio de 1939. Como director de la publicación figuraba José Inalaf Navarro; como administrador Ernestro Lepín Marimán y como principales redactores Alberto Melillán y Felipe Inalaf. En esta primera edición, aparece un señero texto de un joven Carlos Huayquiñir de apenas 26 años. También escriben Domingo Tripailaf, Norberto Pichilaf y Domingo Curaqueo.

En su primer número, El Frente Araucano navega por los temas que la Sociedad Galvarino considera pilares de su identidad política y su quehacer intelectual: la denuncia contra los abusos producidos por los despojos territoriales, la lucha contra las malas prácticas internas como el alcoholismo, las diferencias políticas con otras agrupaciones y el llamado a juntarse y organizarse como mapuche en el lugar donde fuere. A modo de editorial, la institución escribe un texto llamado "Nuestro Propósito", donde expresa sus principales definiciones: 
Hace 7 años: el 10 de julio de 1932, un grupo de jóvenes araucanos residentes en Santiago convinieron en echar las bases de una sociedad indígena con el nombre de "Sociedad Araucana Galvarino", cuyo objetivo principal fue la defensa la "Raza", tan ultrajada, vilenpendiada y expoliada en sus justos y legítimos derechos, sobre todo en lo referente a sus tierras heredadas y defendidas por sus padres y abuelos hasta entregar sus vidas en aras de ellas (...)

La "Sociedad Araucana Galvarino" a través de sus 7 años de existencia modesta, pero efectivamente ha hecho una gran labor a favor de sus compatriotas mapuches $(\ldots)^{2}$

Convencidos de la labor que realizaba la Sociedad, sus integrantes plantean con meridiana claridad la precariedad del diario en circulación: "este periódico adolecerá, sin duda, de muchos defectos, ya que sus dirigentes no son periodistas ni aficionados" ${ }^{3}$, pero al mismo tiempo reconocían su relevancia, cuyo cometido podría resumirse en difundir lo que ellos denominan "los éxitos y fracasos" del pueblo mapuche.

A partir del cuarto número del periódico, Carlos Huayquiñir asume la dirección y participa en la redacción de varios de los artículos ${ }^{4}$. Asimismo, responde las Cartas al Director y poco a poco va adquiriendo un rol más protagónico. En junio de 1940, se acaba el corto ciclo de El Frente Araucano ${ }^{5}$, dando paso a un nuevo diario de la Sociedad Galvarino: el Heraldo Araucano, cuya primera edición se publica en septiembre de $1940^{6}$. El Heraldo, en cuya bajada se lee Galvarino piñechi mapuche sociedad tañi diario ta t'ufá, también es dirigido por Carlos Huayquiñir. En el saludo inicial del periódico se lee: "queremos ser los continuadores de la tradición de lucha que supo mantener El Frente Araucano, queremos en verdad ser los heraldos de la raza" 7 .

La participación de Carlos Huayquiñir irá creciendo al interior de la Sociedad Galvarino. Asume el cargo de tesorero en 1939 cuando la institución estaba bajo la presidencia de José Inalaf. Y dos años después, es electo presidente, mención que dura hasta diciembre de 1942. En su despedida oficial del cargo de presidente y también de la dirección del diario, se publica por primera vez una fotografía de este joven hombre a modo de homenaje por la labor realizada. No obstante, Huayquiñir continuaría dirigiendo el periódico durante 1943.

${ }^{2}$ El Frente Araucano, año I, número 1, p.3, julio de 1939. Santiago de Chile.

3 Ídem.

${ }^{4}$ El Frente Araucano, año II, número 4, abril de 1940. Santiago de Chile.

${ }^{5}$ El Frente Araucano, año II, número 5 y 6, p.3, junio de 1940. Santiago de Chile.

${ }^{6}$ Heraldo Araucano, año I, número 1, septiembre de 1940. Santiago de Chile.

${ }^{7}$ Heraldo Araucano, año I, número 1, p.1, septiembre de 1940. Santiago de Chile. 


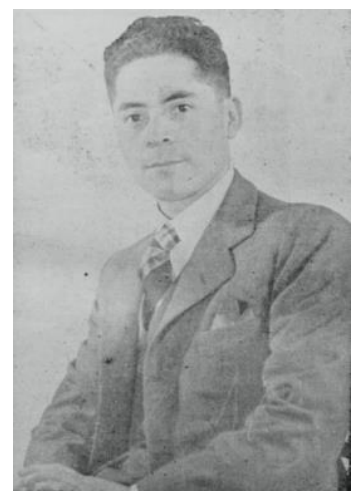

Figura 1: Carlos Huayquiñir Rain. Imagen en el Heraldo Araucano, año III, número 3, diciembre de 1942, p. 3, Santiago.

El Heraldo Araucano, en cuanto a la política chilena, tenía cercanía y respeto por la figura de Pedro Aguirre Cerda, cuyo corto gobierno (1938-1941) marcó las posiciones de la Sociedad Galvarino, sobre todo en materia de educación. De hecho, algunos miembros de la Sociedad fueron activos militantes del Frente Popular en las etapas previas al triunfo de 1938 y durante el proceso (Acevedo, 2019, p.125-126). En cuanto a la política mapuche, levantaba una posición muy cercana al Frente Único Araucano, cuyas actividades y congresos tendrán una amplia cobertura.

En la década del 1950, Carlos Huayquiñir asume la dirección del diario Acción Araucana, otra publicación radicada en Santiago de Chile. Su primer número es de julio de 1953. Esta vez, el contexto político mapuche es distinto y en sus páginas se expresa la proximidad y sintonía con la Corporación Araucana. Al parecer, Huayquiñir se ha distanciado de la Sociedad Galvarino, quienes ahora tienen un nuevo periódico. El Heraldo Araucano ha quedado atrás y ahora es La Cultura su órgano de difusión, bajo la dirección de José Alcapán ${ }^{8}$. El año 1953 es clave para el movimiento mapuche. La Corporación Araucana logra la elección de José Cayupi y Esteban Romero como diputados por Temuco. Pero además se suma a esto un número importante de regidores y alcaldes (Ancán, 2010, p.12).

La Corporación Araucana es, para la década del cincuenta, la organización mapuche más poderosa. Desde se fundación en 1938, como fusión de la Sociedad Caupolicán y la Federación Araucana, sus integrantes delinearon una estrategia de consecución de poder político por la vía electoral (Ancan, 2010). Venancio Coñuepán aparece como su figura mediática más fuerte. Su camino como referente dirigencial viene destacándose desde antes, siendo un hito relevante su participación en el Congreso

\footnotetext{
${ }^{8}$ La Cultura, año I, número 1, pp.1-2 y 8, 1 de diciembre de 1953. Santiago de Chile. 214 | AlpHA № 53 (DiCIEMBRE 2021) PÁGS. 209-229. ISSN 07 16-4254
} 
Indigenista Interamericano de Pátzcuaro (México) en 1940, donde expresa gran parte de las ideas que, como semillas, pronto florecerán. Según la investigación de Jorge Iván Vergara y Hans Gundermann (2016), en la presentación de César Colima y Venancio Coñuepan en México ya se hablaba de la creación de una subsecretaría de asuntos indígenas en el gobierno. La ponencia de los dirigentes habría mezclado posturas de un integrismo estatal, pero también algunas medidas bajo la convicción de seguir siendo

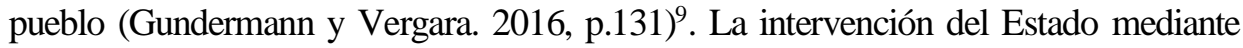
políticas indigenistas, se volvió una de las convicciones más significativas de la Corporación Araucana, lo que se materializó, por un lado, con el nombramiento de Venancio Coñuepán como Ministro de Tierras y Colonización en 1952 durante el gobierno de Carlos Ibáñez del Campo; por otro, con el surgimiento de la Dirección de Asuntos Indígenas (DASIN) en 1953 (Vergara, Foerster y Gundermann, 2006).

La escritura de Carlos Huayquiñir en 1953 devela una estrecha relación con la Corporación Araucana. En marzo del año anterior, se abrió una filial de la Corporación en Santiago, conformada además por Lorenzo Lemuguir, Alfredo Huincahue, Martín Treumún (Huayquiñir, 1966, p.11). Este vínculo permite entender la labor política del diario. El periódico describe a la Corporación como la "monitora indiscutible de la raza indígena del país". En sus páginas se enaltece la figura de Venancio Coñuepán, en específico, al revisar las gestiones del ministro en el caso de la comunidad Bernardo Nanco de Lonquimay contra explotadores madereros ${ }^{10}$. También se hacen llamados a actividades de financiamiento para los diputados José Cayupi y Esteban Romero. El periódico convoca de manera explícita a los mapuches de Santiago a participar de la Corporación Araucana:

Hermano, tus hermanos de raza te invitamos a que llegues a nosotros y te unas con quienes, como nosotros, llevan tu sangre, hablan tu lengua, siente como tú y tiene tu propia alma. Te invitamos a que vengas a dar tu adhesión honrada, leal y decidida a esta acción indígena de bien común. No traiciones con tu indiferencia. La suerte tuya y la de toda tu raza está en juego, nuestra raza fundadora de la nacionalidad. Asiste a nuestras reuniones todos los sábados a las 19 horas en Moneda $1590^{11}$.

En1966 Carlos Huayquiñir publica su revista Arauco de ayer y de hoy huiyá ka fachiántï, autoeditada en Santiago, en cuya portada figura como Órgano de publicidad cultural y asistencial e investigaciones autóctonas de Chile ${ }^{12}$. Para estas fechas,

\footnotetext{
${ }^{9}$ La Conferencia de César Colima y Venancio Coñuepán puede leerse en la página web Intercultural Conversation, disponible en: http://interculturalconversations.com/\#/explore/archive/sm45

${ }^{10}$ Acción Araucana, año 1, número 1, julio de 1953, p.1 Santiago de Chile

${ }^{11}$ Acción Araucana, año 1, número 1, julio de 1953, p.3. Santiago de Chile

${ }^{12}$ En su primera página, Carlos Huayquiñir agradece a la doctora Cristina Palma Prado, Jefa de la sección de Educación para la Salud del Servicio Nacional de Salud por la colaboración en el proceso de publicar la revista (Huayquiñir, 1966, p1).
} 
Huayquiñir ya ha cambiado su domicilio político. En 1964 funda junto con Juan Catrilaf y Ramón Lincopán la Corporación Lautarina, a quien representa en las discusiones de la Ley de Reforma Agraria en 1966, junto con un viejo conocido: Alberto Melillán ${ }^{13}$. El contexto de la reforma agita las reflexiones de Huayquiñir, así como también su accionar político. Un memorándum publicado en el libro, respecto a una reunión con el vicepresidente, Bernardo Leighton, así lo deja ver (Huayquiñir, 1966, p.37).

Arauco de ayer y de hoy constituye su obra más visible y su trabajo más citado en diferentes investigaciones. Huayquiñir lo define como un diario, pero circula en formato cuadernillo, libro pequeño o revista de 13 por 18 centímetros. Allí se dejan ver los posicionamientos de Huayquiñir, su mirada del presente y la realidad del pueblo mapuche. Para el autor, tener un periódico propio y autónomo es una conquista, como lo desliza de forma clara en la editorial que presenta la obra. Desde sus primeros textos en El Frente Araucano hasta los sesenta, Huayquiñir ha madurado un periodismo político que lo llena de orgullo. Desde su perspectiva, es por intermedio de este instrumento que "se influye en el pensamiento y se imponen las ideas ante las colectividades, se exalta la verdad y se condenan las injusticias y se consiguen conquistas sociales que sin el diario fuera imposible o utópico obtener" (Huayquiñir, 1966, p.2). Su elocuente visión de la labor informativa lo ha hecho llegar a la convicción que para profundizar en la tarea fijada $\mathrm{y}$, sobre todo para difundir el conocimiento y la historia mapuche, el movimiento y las organizaciones debieran avanzar hacia un Instituto de Investigaciones Araucanas, cuya misión será "salvar del olvido lo nuestro" (Huayquiñir, 1966, p.3).

\section{JUVENTUD MAPUCHE Y EDUCACIÓN}

La escritura de Carlos Huayquiñir intervino en diferentes temáticas por medio de insertos en los diarios como análisis, columnas de opinión, noticias, entre otros formatos. Con el paso del tiempo se transformó en un periodista autodidacta bastante prolífero. En un segmento de Arauco de ayer y de hoy publicita su trabajo, indicando una lista de "periódicos y ensayos sobre el problema indígena en Chile" elaborados por el autor. En este pequeño apartado, acompañado de una fotografía, menciona a El Frente Araucano de 1939, El Heraldo Araucano de 1940, La Voz Araucana de 1943, Acción Araucana de 1953 y Documentos que los Araucanos deben saber de 1953. Recogiendo y sistematizando el abundante corpus textual que legó Huayquiñir a sus actuales lectores se pueden vislumbrar dos tópico centrales: por un lado, su preocupación por la educación y la juventud mapuche y, por otro, en el combate contra el racismo.

\footnotetext{
${ }^{13}$ Biblioteca del Congreso Nacional de Chile. Historia de la Ley 16.640. Disponible en https://obtienearchivo.bcn.cl/obtienearchivo?id=recursoslegales/10221.3/45903/1/HL16640.pdf 
Indudablemente, el acceso a la enseñanza formal para la niñez y la juventud mapuche fue unos de los grandes temas que enarboló el movimiento durante la primera mitad del siglo XX. La Sociedad Caupolicán, la Federación Araucana, la Unión Araucana, el Frente Único Araucano, la Corporación Araucana, La Sociedad Galvarino, entre otras instituciones, promovieron la inserción del mundo indígena en las escuelas, la creación de escuelas técnicas o agrícolas en los territorios y la necesaria instrucción y formación como una herramienta vital para el desarrollo de la sociedad mapuche. Vastas investigaciones han documentado cómo se configuró esta demanda desde el origen del movimiento organizado (Alvarado y Antileo, 2019; Bengoa, 1985; Cárdenas, 2012; Foerster y Montecino, 1988; Marimán, P., 2007a; Menard y Pavez, 2007; Nahuelpán y Marimán, P., 2008; Ramay y Loncón, 2016). La dirigencia de esta época depositó sendas esperanzas en la educación de las nuevas generaciones. A partir de la instrucción, los intereses del pueblo podrían defenderse de mejor manera y de paso combatir el imaginario chileno sobre lo mapuche, incrustado en una visión del indígena como rémora del siglo XIX, es decir, en un ideario de lo bárbaro y lo salvaje.

Los primeros textos de Huayquiñir avanzaron en esta dirección, entusiasmando a las y los jóvenes a trabajar por su pueblo. En "El deber de la Juventud Araucana" de 1939, Huayquiñir señala que "la única salvación de la raza aborigen está en sus hijos, la juventud araucana es nervio y esperanza de la Araucanía"14. En su texto "Lectores y Favorecedores" de 1940, junto con agradecer a quienes hacen posible la circulación del diario El Frente Araucano, el autor enfatiza que la función de publicación es un servicio donde "se vacíen el pensamiento y aspiraciones de la colectividad y se encaucen los esfuerzos de nuestros hombres jóvenes, esperanza y símbolo de un mejor porvenir para la raza de Lautaro y Caupolicán"15.

En los textos de Carlos Huayquiñir, así como en muchas y muchos de sus contemporáneos, se agita una esperanza renovadora. Los congéneres de Huayquiñir-que entre 1930 y 1940 están atravesando los veinte años- pulsan un cambio que interpela a la dirigencia mapuche de generación anterior, hablamos de Manuel Manquilef, Francisco Melivilu, Avelino Ovando, Manuel Aburto Panguilef, entre otras figuras. Si bien respetan y admiran a sus predecesores, quieren tener un rol más activo en la política mapuche. Depositan su fe en un mañana donde el pueblo mapuche esté dirigido por un grupo de jóvenes preparados. Y con preparación se refieren a estudios formales. En el diario de 1966, Huayquiñir demuestra su tremendo orgullo por los profesionales mapuches de la época, felicitando públicamente a las doctoras Fresia Pichún y Zoila Huichalaf, a los doctores Ignacio Huenchullán y Alejandro Leñam, así como a los ingenieros agrónomos Nepuceno Paillalef, Zenón Leñam y Miguel Colompil, ingenieros civiles como Víctor

\footnotetext{
${ }^{14}$ Frente Araucano, año I, número 1, p. 4, julio de 1939. Santiago de Chile.

${ }^{15}$ Frente Araucano, año II, número 4, p.3, abril de 1940. Santiago de Chile.
} 
Quilaqueo y a los abogados Pedro Leñám, Víctor Raulí Nahuelpán, Arturo Huenchullán, Antonio Antileo, Luis Chureo (Huayquiñir, 1966, p.1).

En cierta medida, en su trayectoria como escritor, Carlos Huayquiñir ha insistido de manera permanente en que las familias envíen a sus hijos al colegio. Para comprender la importancia que adquiere esta batalla por la educación de la niñez y la juventud mapuche, es necesario situar su autoría en la genealogía de una demanda que comienza en los albores del siglo XX y que contó con figuras claves como Manuel Neculmán, Manuel Manquilef, Arturo Huenchullán, Herminia Aburto, Zoila Quintremil, Margarita Jaramillo, entre muchas otras personas, y que además constituyó un elemento transversal en la mayor parte de las organizaciones mapuches (Foerster y Montecino, 1988).

En este ejercicio de situar en una temporalidad las ideas del autor, es preciso identificar la pulsión educacional en varias escritoras y escritores contemporáneos a Huayquiñir, quienes proclaman la urgencia del estudio en el seno de las familias mapuches, haciendo un llamado a no negar esta posibilidad a los niños. Emilio Huenuhueque, por ejemplo, escribía en 1937: "los padres araucanos no deben negarle la educación a sus hijos porque la educación es la única herencia que deben dejarle a su familia. Parece que nosotros solo pensamos en aprovecharles en el trabajo a los niños"16. El mismo reclamo proclamaba dos años antes Herminia Aburto Colihueque, pero esta vez haciendo ahínco en las mujeres mapuches, instando a "que los padres y madres deben mandar a sus hijas al colegio para que reciban, aunque sea una pequeña educación y puedan ser más tarde un elemento útil para la raza"17.

Como es plausible sostener, la lucha de Huayquiñir tenía varios antecesores y contemporáneos que insistían en la relevancia de educarse. Floriano Antilef, miembro de la Unión Araucana, era uno de ellos. En 1937 expuso las divergencias que cohabitaban en el mundo mapuche en torno a este tema. Planteaba una disputa entre elementos de lo que denomina el "Viejo Arauco" que sostenían que "los mapuches deben seguir el antiguo modo de vivir y las antiguas costumbres, que no deben perder las tradiciones de sus abuelos"18 y el "elemento joven" que observa la ignorancia como el principal problema social mapuche. No obstante, Antilef advierte que educarse no significa despreciar la cultura y las tradiciones, sino más bien podría traducirse como un acto muy estratégico.

La cuestión de la educación para la niñez y la juventud mapuche en este punto aparece como un elemento contradictorio o paradójico entre la demanda política y la experiencia subjetiva en la escuela. Algunos investigadores han puesto énfasis en estos últimos aspectos. Por ejemplo, el trabajo de Juan Porma aborda la violencia física y psicológica en la memoria de niños que pasaron por la escuela en Nueva Imperial,

\footnotetext{
${ }^{16}$ El Periódico Araucano, año I, número 4, p.1, marzo de 1937. Nueva Imperial

${ }^{17}$ Diario de la Federación Juvenil Araucana, número 1, p.5m septiembre de 1935. Nueva Imperial

${ }^{18}$ El Araucano, año I, número 5, pp 2-3, noviembre de 1937. Padre Las Casas.

218 | AlpHA № 53 (Diciembre 2021) PÁGS. 209-229. ISSN 07 16-4254
} 
profundizando en el castigo y en el abandono del mapuzugun como expresiones de la violencia colonial (Porma, 2015). También Héctor Nahuelpán ha visto la escuela por medio del concepto de espacios civilizatorios, tomado de la investigadora maya Aura Cumes. Nahuelpán define esta noción como "espacios e instituciones (...) donde los Mapuche en tanto sujetos colonizados, debían disciplinarse como súbditos, sirvientes o ciudadanos de segunda categoría, e ir incorporando un conjunto de hábitos, costumbres y valores, que posibilitarían su cambio cultural" (2013, p. 142). Desde esta perspectiva, la escuela -fiscal o misional- era un medio para el adoctrinamiento, la chilenización, la cristianización, el disciplinamiento de los cuerpos mediante la enseñanza de oficios y sobre todo para la colonización ideológica.

¿Cómo es posible que la configuración de la escuela como un espacio traumático o de castigo para muchas generaciones mapuches fuera también la base para la demanda por educación que sostenía el movimiento mapuche y muchos escritores y escritoras, entre esos Huayquinir?

A mi juicio, quienes pregonaban por mayores alcances del sistema educativo para la sociedad mapuche tenían muy claro que la violencia, como lo ha sostenido el pensador boliviano Marcelo Sarzuri-Lima, era una característica implícita y constante del modelo de enseñanza (Sarzuri-Lima, 2013, p.8). Existía plena conciencia, como veremos más adelante en autores como Domingo Curaqueo o Martín Alonqueo por ejemplo, de las limitaciones de la escuela y su rol reproductor de la violencia colonial. No obstante, las trabas y dificultades, el ingreso y el paso por estas instituciones se volvía en absoluto necesario para las nuevas generaciones. He ahí un fundamento político que subyace en esta defensa, un fundamento que es estratégico y que está velando por el bienestar colectivo del pueblo mapuche que debía sacrificarse para conseguirlo.

El llamado a la instrucción o la educación -aunque está atravesado por una idea civilizatoria o incluso cristianizadora entre muchos de sus alentadores mapuches-, desde mi perspectiva, deviene en una aspiración política medular centrada en pensamientos como la dignificación y la defensa de los intereses del pueblo. Estas dos ideas, que viajan por las páginas de los diarios mapuches, serán refrendadas por múltiples voces en aquel momento histórico, haciendo eco de un horizonte político común de quienes entienden que en el deber de instruirse está en juego el futuro de la colectividad. Allí se enaltece la formación como una garantía de protección contra los abusos de colonizadores, usurpadores y tinterillos. "No pasareís más adelante, abusadores de la ignorancia", declamaba Martín Alonqueo en un señero texto de $1937^{19}$, haciendo alusión a los engaños en la compra de tierras. "Pero a pesar de todo, aún tenemos una juventud estudiosa y con aires marciales se esfuerzan por levantar a su raza", planteaba Norberto Pichilaf cuando comentaba los abusos de los latifundistas ${ }^{20}$.

${ }^{19}$ El Araucano, año I, número 1, p.1, julio de 1937. Padre Las Casas.

${ }^{20}$ Heraldo Araucano, año III, número 3, p.2, Febrero de 1943. Santiago de Chile. 
Además, la noción de dignidad aparece en reiteradas ocasiones, tanto en Huayquiñir como en otras y otros escritores, apelando a luchar contra los imaginarios que vapulean las formas de existencia mapuche. Dignificar, en el pensamiento de Huayquiñir, podría traducirse como valorarse, quererse, mirarse ya no como rémoras del pasado sino en la construcción del futuro. En este punto es donde se articula un pensamiento contra el racismo chileno que revisaremos a continuación.

\section{RACISMO Y DIGNIDAD EN LA PROSA DE HUAYQUIÑIR}

Antes de avanzar en los trazos que Carlos Huayquiñir articuló para defender al pueblo mapuche de los ataques racistas de la época, es necesario hacer una advertencia para comprender de mejor manera a los escritores y escritoras anteriores y contemporáneos al autor estudiado. En varios pasajes, la dignidad de la raza es la idea que conjuga y condensa la lucha contra el racismo. Pero esta idea de "raza" no tiene su anclaje en aspectos biológicos ni en discursos racialistas, entendiendo estos procesos de racialización como una selección de diacríticos para marcar la alteridad (Briones 2002, Domínguez 1994). Esta noción de "raza" se orienta más bien a la definición de una colectividad histórica, una nación o un pueblo, pero sin nombrar estos conceptos. Se produce allí una apropiación de las categorías que la sociedad chilena ha utilizado históricamente como referencias -llámase indio, llámese raza- para denominar al pueblo mapuche. En otras palabras, los mismos léxicos para marcar esa otredad incómoda son reutilizados por la dirigencia mapuche, pero esta vez para alterar sus sentidos y mencionarse a sí mismos.

Por cierto, este impulso es temprano en las letras mapuche. En su libro Las tierras de Arauco (1915), Manuel Manquilef hace una larga exposición de elementos políticos, jurídicos y económicos que perjudicaban al "indio" o a "la raza", refiriéndose al pueblo mapuche. Estos ejercicios de enunciación de la colectividad fueron una característica del movimiento mapuche entre 1910 y los años setenta. Similar apropiación sucedió con la palabra "araucano" que formó parte de las designaciones de un gran número de organizaciones mapuches en el mismo marco temporal. Las reminiscencias a "araucano", "indio", "raza", eran el acervo de autonombramientos más característico en organizaciones como la Sociedad Caupolicán, la Federación Araucana o la Corporación Araucana, por mencionar algunas. También en dirigentes como Manuel Aburto Panguilef, Venancio Coñuepán -que varias veces se presentó a elecciones como el candidato de "la raza" (Foerster y Montecino, 1988-, José Cayupi, Martín Painemal, entre muchísimas otras voces.

Para André Menard y Jorge Pavez, es el sujeto político e histórico el que se manifiesta mediante el concepto de "raza araucana" (2005, pp. 214-215). Sin duda, es aquí donde se debe hacer hincapié para comprender estos vocabularios políticos 
empleados por el movimiento mapuche. Se trata de una apropiación del lenguaje etnológico epocal exhibido en autorías como las de Tomás Guevara, Rodolfo Lenz u otros exponentes de lo que Jorge Pavez (2015) ha llamado el araucanismo chileno ${ }^{21}$. La utilización de estas mismas referencias del araucanismo criollo por parte de las autorías y dirigencias mapuches de aquellos años, dejan en evidencia un claro intento de interlocución y comunicación con la sociedad chilena. El uso del castellano en las escrituras mapuches deviene como la acción más palpable de este llamado a la conversación y son los recursos del castellano y de su contexto sociopolítico los que se desplegarán para exponer la acallada realidad mapuche. Como contracara, en los pocos textos en mapuzugun que se disponen, ya sea por "informantes" o escritos por mapuches, estas autodenominaciones no existen o no tienen la misma relevancia (Alvarado y Antileo, 2019, p.23).

Considerando los elementos anteriores, la dignidad o la dignidad de la raza constituyó uno de los alegatos más poderosos en varios escritores y escritoras mapuches, incluyendo a Carlos Huayquiñir. El objetivo de esta dignificación era el combate contra las ideas y actitudes racistas de la época, mediante una campaña focalizada en la denuncia y en el fortalecimiento del orgullo propio. Ejemplo de esta prosa fue Francisco Levimán, quien en 1938 alentaba la dedicación al estudio y al deporte en la sociedad mapuche. Con convicción señalaba "[c]ontribuyendo de este modo, podemos con orgullo borrar el menosprecio con que nos miran y que hiere nuestra dignidad" 22 . De modo similar se expresaba el escritor del Frente Araucano, Felipe Inalaf, cuando criticaba el maltrato laboral que vivían las y los migrantes mapuches dedicados al empleo doméstico o al rubro panificador en la capital de Chile:

[n]aturalmente, en muchas panaderías y hogares de gente bien nacida, encuentran patrones justos que les pagan legítimamente el salario que merecen, encontrándose también dentro del gremio pocos escrupulosos que les niegan el justo derecho que merecen, a más del pago, de ser considerados con dignidad y consideración. Hay casos aislados en que el araucano, caracterizado de campesino y de escasa instrucción, es objeto de salario irrisorio, de negársele la libreta de Seguro Obligatorio, de pago de los días del feriado anual, y aún más, suelen ser víctimas de vilipendio, diatriba y de otros tratamientos zafios que la cultura de un país debe repudiar $^{23}$.

\footnotetext{
${ }^{21}$ Para profundizar en la noción de antropología chilena en el siglo XIX y XX, y del araucanismo, se sugiere el libro El pueblo mapuche en la pluma de los araucanistas, editado por Héctor Mora y Mario Samaniego (2018), que contiene investigaciones de Héctor Mora, Mario Samaniego, Rodrigo Vásquez, Gabriel Pozo, José Manuel Zavala, José Díaz-Diego y Alejandro Fuentes. Ver bibliografía.

${ }^{22}$ La Voz de Arauco, número 1, p-2, junio de 1938. Temuco

${ }^{23}$ El Frente Araucano, año I, número 2, p.1, septiembre de 1939. Santiago de Chile
}

ALPHA № 53 (DicIEMBre 2021) PÁGS. 209-229. ISSN 07 16-4254| 221 
Pese a que Inalaf realiza una crítica matizada, instalando una noción de excepcionalidad de este tipo de experiencias en su discurso, el autor no duda de los constantes atropellos que viven los y las trabajadoras mapuches, y considera fundamental denunciarlos porque aquella situación solo socava la dignidad de su gente. Los abusos contra los panificadores y las luchas sociales por acabar con estas nefastas prácticas serán resumidos por Carlos Huayquiñir en Arauco de ayer y de hoy (1966, p.37) y, años más tarde, serán contados de manera detallada por Martín Painemal Huenchual en la biografía que redactó el antropólogo Rolf Foerster (1983), uno de los primeros testimonios mapuches en esta materia.

Carlos Huayquiñir se sumó a muchos de sus contemporáneos en el enfrentamiento intelectual contra el racismo. Respondiendo a distintas afrentas raciales, su prosa esgrimió una constante lucha entre 1940 y 1966, vislumbrando en su quehacer escritural las diversas sinuosidades por donde transitaba este tipo de agresiones. El 1940, Huayquiñir en su artículo "Defendámonos" refutaba una presentación en el Rotary Club de Temuco hecha por el empresario Carlos Mahuzier y publicada en el Diario Austral, señalando lo siguiente. Cito en extenso:

Con cierta frecuencia, desde un tiempo a esta parte, hay quienes se han dedicado a hacer a los aborígenes de Arauco blanco de injustas calumnias y suposiciones que generalmente culminan con el insulto audaz y desmañado (...) No importaría que estos ataques a mansalva, villanos por su fondo y naturaleza, provinieran de personas que no tienen solvencia moral o que fueran esporádicos como es natural en el desfogue de las pasiones que suelen azotar a personas descontroladas. Pero es significativo que a veces estos ataques adquieran una continuidad que hace pensar en una campaña emprendida quien sabe con qué fines inconfesables. Tal [como] ha estado sucediendo este último tiempo en que con diversos pretextos y audaces aseveraciones se ha estado denigrando el buen nombre de Arauco y de su raza.

Ante esta situación abominable por naturaleza, creemos que debe cesar la políica de indiferencia y apatía que la raza ha mantenido y debemos defendernos con la prensa, con los hechos y con las palabras.

Se nos dice que somos una rémora para el progreso; que somos incultos, alcohólicos, bárbaros; que estamos en decadencia; que no sabemos administrar lo nuestro y que no tenemos mayores aspiraciones.

Pues bien, demostrémosle lo contrario. Mostremos que somos más grandes y capaces que los que nos atacan; mostremos que sabemos responder al insulto con la acción de los pueblos honestos y viriles que saben mostrar sus virtudes y exhibir las muestras de un pasado glorioso y de un presente fecundo. Hay que terminar con estas campañas. Debemos hacerlas concluir y debemos usar todos los medios que están a nuestro alcance para hacer que se nos respete y que se nos dé el lugar que 
merecemos en la población de este Chile del cual algunos menguados quisieran veros desaparecer, lo que no conseguirán jamás de los jamases. ${ }^{24}$

En este escrito, haciendo eco de las respuestas emanadas de la Corporación Araucana y del Frente Único Araucano, Carlos Huayquiñir critica la continuidad de la campaña de despretigio contra el pueblo mapuche -que tiene espacio en los medios de comunicación- y hace un llamado a la defensa. Estos eran los años en que el "cinturón suicida" era la metáfora para referirse a las reducciones mapuches de los alrededores de Temuco como un problema o obstáculo para el crecimiento y desarrollo. Ese era el lenguaje que políticos y empresarios imponían en los medios de comunicación (Foerster y Montencino, 1988, p. 129; Bengoa, 1985[2008], p. 337).

Por cierto, todos los imaginarios negativos y los prejuicios a los que responde Carlos Huayquiñir son elementos característicos de los procesos de racialización de la población indígena, afincadas sobre todo en un ideario supremacista. El racismo debe entenderse sobre todo como una construcción de la inferioridad del otro (Memmi,1986; Williams 1944 [2011]), cuyo propósito es la explotación y sometimiento de aquella alteridad por medio de este patrón de poder (Quijano, 2000). Como bien lo ha definido el sociólogo francés Michel Wieviorka: "consiste en caracterizar a un conjunto humano mediante atributos naturales asociados a su vez a características intelectuales y morales aplicables a cada individuo relacionado con este conjunto, y a partir de ahí adoptar algunas prácticas de inferiorización y exclusión" (2009 [1998], p.13). Fueron estos elementos los que configuraron el escenario racista chileno experimentado por generaciones de mapuches en el campo y la ciudad durante todo el siglo XX.

La experiencia racista y su sedimentación fueron el blanco al que apuntaban Carlos Huayquiñir y otras autorías mapuches en su quehacer intelectual. El racismo tenía diversas facetas, escenarios y mecanismos de operación. Uno de los más significativos para el autor fue el campo de la educación. Como lo han planteado diferentes investigadores, el racismo es un producto histórico o una formación que adquiere además distintas características según contextos específicos (Omi y Winant, 1994; Wallerstein y Balibar, 1991 [1988]). Fueron esas particularidades las que Huayquiñir fue observando en sus columnas y a las que dedicó críticas como esta, referidas a la enseñanza de la historia:

[los araucanos] estiman, y esto no como un favor, sino en mérito a la verdad y en honor a la realidad, que, respecto de Arauco, respecto del indio, la Historia y su manera de enseñarla deben reformarse de plano.

Es cosa corriente y moliente en que los encargados de enseñar la Historia presente al Araucano como el desechado de cuanto vicio y perversión pueda imaginarse, que le nieguen, no solamente la civilización, sino también los sentimientos de hombre. Y esa falsa idea del aborigen se perpetúa y queda estereotipada en la mente

${ }^{24}$ Heraldo Araucano, año I, número 1, p.3, septiembre de 1940. Santiago de Chile. ALPHA № 53 (DiCIEMBRe 2021) PÁGS. 209-229. ISSN 07 16-4254| 223 
de los niños con frases semejantes a esta: "flojo como un indio", "feo, como un indio" y "grosero como un indio", etc.

Hora es ya de terminar con esa manera de enseñar que se nos antoja esencialmente antipedagógica. Ni la indolencia propia del Araucano era flojera, ni su falta de civilización europea. El indio vivía en su ambiente propio y en su medio era digno y era honesto. No queremos decir que se presente a nuestros antepasados como un prototipo de virtudes cristianas, pero tampoco nos es dable tolerar el que se nos muestre como ejemplares de perversión ${ }^{25}$.

En este texto de 1941, llamado “Arauco ante la campaña de la chilenidad", Carlos Huayquiñir analiza la construcción de imaginarios y su reproducción en la enseñanza. La flojera, la fealdad, la barbarie como oposición a civilización, son recurrencias que tendrían un fuerte impacto sobre todo en la niñez. La conformación de prejuicios, que son una forma elemental de racismo (Wieviorka, 2009 [1998], p.72), en la perspectiva de Huayquiñir alimentan una animadversión contra el indígena. Esta opinión era compartida también por el profesor Domingo Curaqueo, quien cuestionaba la labor pedagógica, preguntándose "¿cuál es el motivo que movió antes al personal docente a perseguir a la raza araucana?"26. Tanto para Curaqueo como para Huayquiñir, esta situación debía ser combatida en las mismas aulas. La educación necesitaba velar por una valoración del pueblo mapuche, prefigurando una transformación que comenzará a producirse varios años después: interculturalizar la enseñanza. A mi juicio, en la visión política de Carlos Huayquiñir, la niñez y la juventud mapuche debían realizar un sacrificio para ingresar y mantenerse en el sistema educativo y para soportar las afrentas racistas enmarcadas en su formación, con el objetivo de poder convertirse en miembros valiosos para su pueblo.

Muchos de los textos de Huayquiñir escritos en la década del cuarenta y cincuenta están nadando contra la corriente de imaginarios racializados y sedimentados en la sociedad chilena. El reclamo, sin lugar a duda, es diferente al que ahora enarbola el movimiento mapuche (Foerster 1999, Pairicán, 2014), vinculado a la emancipación, la territorialidad y la autodeterminación de los pueblos. El pensamiento del autor se inscribe en una reivindicación por derechos civiles (Alvarado y Antileo, 2019, p.20). Su argumentación se sostiene en la necesidad de ser considerados en la "chilenidad", concepto que evoca el deseo de ser tratados en la misma condición de ciudadanía que los chilenos y no como personas inferiores.

Para varios escritores y escritoras coetáneos, el pueblo mapuche que acaba de ser incorporado por medio de la guerra y el despojo a fines del siglo XIX, es humillado de manera permanente por los políticos chilenos, por la prensa y por el sistema escolar (Curaqueo, 1938; Pichilaf, 1943; Leñam, 1953). Se sienten ciudadanos de segunda

\footnotetext{
${ }^{25}$ Heraldo Araucano, número 2, p.3, julio-agosto de 1941. Santiago de Chile.

${ }^{26}$ Heraldo Araucano, número 1, p.1, septiembre de 1940. Santiago de Chile.

224 | Alpha No 53 (Diciembre 2021) PÁGS. 209-229. ISSN 07 16-4254
} 
categoría y añoran conseguir que "se nos dé el lugar que merecemos en la población de este Chile", como lo indicó Huayquiñir en 1940.

La insistencia de Carlos Huayquiñir en este punto fue notable. Él veía una actitud sistemática contra el pueblo mapuche, que bien puede ser leída desde una perspectiva racista. En su artículo "Mensaje contra el odio, la aversión indígena debe terminar..." de 1966, Huayquiñir se esforzaba por obtener el reconocimiento del mundo chileno, valorando o incluso exacerbando el pasado épico de luchas indígenas contra la Corona española e intentando erradicar esta visión de enemigo que pesa sobre los mapuches. En su prosa, explicaba que su pueblo no deseaba "araucanizar al país", como se acusaba en la época; que su pueblo alentaba su proceso de instrucción, educación y civilización. Con ese lenguaje, el autor quiere agrietar el discurso de "aversión contra el indígena" y tener un espacio en esta "chilenidad". No obstante, al demandar este lugar, lo hace sin abandonar la historia y la cultura mapuche, de la que se siente en especial orgulloso y defensor (Huayquiñir, 1966, p.20-21).

Estas argumentaciones de la "chilenidad", que en un principio pueden parecer confusas, han sido estudiadas en el caso de otros intelectuales mapuches como Manuel Manquilef por medio del concepto de "doble conciencia". La historiadora Florencia Mallon (2010), haciendo referencia al conocido intelectual afroamericano estadounidense William Edward Burghardt Du Bois (1903) en sus reflexiones sobre ser "americano" y ser "negro", explica la articulación de una conciencia de la colonización y el despojo en Manquilef, con la conciencia de integración al modelo de desarrollo chileno. En el caso de Huayquiñir, coexiste una conciencia del maltrato racial contra el pueblo mapuche, a la vez que un sueño de pertenencia y reconocimiento en la "chilenidad".

Ahora bien, como un punto específico de esta reflexión, creo necesario resaltar un aspecto clave en el pensamiento de Huayquiñir: su convicción de la autonomía mapuche. Pero no es la autonomía que hoy entienden y sostienen organizaciones y dirigentes, en términos políticos o territoriales (Marimán, J., 2012). La autonomía a la que apela Huayquiñir refiere a la capacidad del mismo pueblo mapuche de revertir el complejo escenario en el que debe desenvolverse. Ante los ataques, el despojo y la ignominia, le asiste la convicción que serán solo las personas mapuches quienes puedan defenderse a sí mismas. No existe en aquel contexto algún posible protector. Son las propias iniciativas mapuches, individuales y colectivas, las que lograrán los cambios necesarios en la convivencia con el mundo chileno. Allí se erigen sus ideas respecto de la educación o planteamientos como el Instituto de Investigaciones Araucanas (Huayquiñir, 1966, p.5). Allí el fundamento de iniciativas como las que expone en su artículo "Arauco y la cinematografía educativa" para impartir enseñanza hasta en la reducción más apartada (1966, p.21) o propuestas como el mausoleo mapuche (1966, p.38), entre otras proposiciones que emergen de su escritura. El camino antirracista trazado por Huayquiñir, si bien hace un llamado a la sociedad chilena a la comprensión, se asienta 
por sobre todo en la propia sociedad mapuche, proyectando sus esperanzas en la juventud y su educación.

\section{A MODO DE CONCLUSIÓN}

Como puede apreciarse en este artículo e investigación exploratoria, la figura de Carlos Huayquiñir Rain en tanto pensador mapuche entre la década de 1940 y 1960 no ha sido estudiada a fondo. Más bien es un autor desconocido de las letras mapuche, al igual que muchos otros de sus contemporáneos. Este trabajo ha querido aportar en la visibilización de su quehacer intelectual y periodístico, a partir de algunas temáticas que emergen de su prosa.

Siendo parte de una segunda generación posreduccional inscrita en el desarrollo del colonialismo republicano (Antimil y Nahuelpán, 2019), Huayquiñir enfrentó un contexto histórico particular lleno de transformaciones en curso que incidieron en su pensamiento. El proceso de división de las reducciones, la instalación y violencia de los colonos, la labor de los tinterillos en las usurpaciones de tierras y los procesos migratorios y de inserción laboral en Santiago, tienen su lugar en la escritura de Carlos Huayquiñir.

En un esfuerzo por sistematizar su producción en los diarios mapuche que circulaban por aquellos años, he planteado dos elementos, a mi juicio, centrales en el pensamiento de Carlos Huayquiñir, que además se encuentran interrelacionados. El primero de ellos es el abordaje del autor en relación con la temática educacional, en un amplio sentido, destacando las esperanzas del autor en la instrucción y formación de la juventud mapuche, pero también la problematización de la institución escolar como reproductora de las prácticas racistas. El segundo elemento es el pensamiento antirracista de Huayquiñir, expresado en sus críticas a la labor docente, a los políticos y a la prensa chilena. El combate al racismo impulsado por el autor tenía como principal agente transformador a la propia sociedad mapuche, insistiendo en iniciativas autónomas que allanarían el camino para un mejor porvenir de su pueblo.

Del mismo Carlos Huayquiñir aún queda mucho por recorrer. Sus periplos, su participación en el Tercer Congreso Indigenista Interamericano realizado en Bolivia en 1954 (Huayquiñir 1966, p. 30), su biografía en general y otras escrituras aún no halladas son caminos para continuar indagando en su labor intelectual.

También su camino como escritor en treinta años deberá sopesarse en futuros estudios y ser un punto desde el cual mirar su producción intelectual. Aquel Huayquiñir que fue observado en 1948 por Manuel Aburto Panguilef con cierta resignación como un joven desatento (Aburto, 2013, p. 398), ya no es el mismo en la parte final de los sesenta. Arauco de ayer y de hoy fue escrito pensando sobre todo en la nueva juventud mapuche, como una suerte de llamado de alerta para que no olviden su historia, para que no pierdan su lengua y para que no dejen de luchar por su pueblo. A sus 53 años, este prolífico 
escritor mapuche estaba preocupado. Veía que las nuevas generaciones saben "nada o muy poca cosa" (1966, p.5). La tradición, la cultura y la lengua mapuche constituían nuevos tópicos del autor. Antes no habían tenido tanto espacio entre los llamados a educarse y los esfuerzos por demostrar que su pueblo no era "un vestigio del pasado". Al parecer, el paso de los años en Santiago evidencia desapegos y desarraigos entre los mapuches y su historia y Huayquiñir quiere hacer algo al respecto, poniendo su prosa a disposición. Aquellas transformaciones en su quehacer intelectual deben seguir escudriñándose.

Este trabajo espera contribuir al conocimiento de la historia del pueblo mapuche y de sus escritores. Como se planteó antes, las investigaciones deben seguir profundizando en las escrituras mapuches. Y no solo en torno a Carlos Huayquiñir, sino considerando los varios autores y autoras que a través de la palabra escrita fueron alzando la voz para pensar el devenir de su gente. Autorías como las de Alberto Melillán, Domingo Curaqueo, Herminia Aburto, Laura Nahuelpán, José Inalaf, Norberto Pichilaf, Víctor Leñam, Antonio Chihuailaf, José Alcapán, entre muchos otros, nos invitan a continuar profundizando en los derroteros de sus ideas y de su trabajo político. Son escrituras muchas veces invisibilizadas por el rol protagónico de las organizaciones más reconocidas de este período mencionadas de manera previa, incluso obnubiladas por la camada de dirigentes que ocupó altos cargos de votación popular o participaron en los gobiernos de aquellos años. Se abren así amplias posibilidades de indagación histórica y de análisis en el campo del quehacer intelectual en un contexto político-social de suma importancia para comprender el presente de la sociedad mapuche y el desarrollo de sus organizaciones y sus utopías.

Artículo suscrito al Proyecto Fondecyt Postdoctorado 3200517 Etapa 2020.

\section{OBRAS CITADAS}

Acevedo, Nicolás (2019). ¿Un racismo en la izquierda? El Partido Socialista, las organizaciones Mapuche y la colonización agrícola (1932-1941), en Revista Divergencia 13(8), 115-13.

Alvarado, Claudio y Enrique Antileo (2019). Diarios Mapuche 1935-1966. Escrituras y pensamientos bajo el colonialismo chileno del siglo XX. Ediciones Comunidad de Historia Mapuche

Ancán, José (2010). Venancio Coñuepan Paillal. Editorial Usach.

Bengoa, José (2008). Historia del Pueblo Mapuche siglo XIX y XX. LOM. (original publicado en 1985)

Bengoa, José y Valenzuela, Eduardo (1984). Economía Mapuche. Pobreza y subsistencia en la sociedad mapuche contemporánea. PAS. 
Briones, Claudia (2002). Mestizaje y blanqueamiento como coordenadas de aboriginalidad y nación argentina, en Runa XXIII: 61-99.

Cárdenas, Mauricio (2012). "La Sociedad Caupolicán Defensora de la Araucanía", en Revista Andes del Sur 7: 43-75.

Curaqueo, Domingo (junio de 1938). La timidez del araucano. La Voz de Arauco, número 2 año 1 . Temuco

De Ramón, Armando (1990). La población informal. Poblamiento de la periferia de Santiago de Chile 1920-1970, en Revista Eure 16 (50): 5-17.

Domínguez, Virginia (1994). A Taste for "the Other". Intellectual Complicity in Racializing Practices, en Current Anthropology 35(4): 333-348.

Foerster, Rolf (1983). Martín Painemal Huenchual. Vida de un dirigente mapuche. Grupo de Investigaciones Agrarias.

Foerster, Rolf y Montecino, Sonia (1988). Organizaciones, líderes y contiendas mapuche (1900-1970). CEM.

Leñam, Víctor (agosto de 1953). Dos tendencias están luchando. El Periódico Araucano número 1, época 6. Padre Las Casas.

Mallon, Florencia (2010). La "Doble Columna" y la "Doble Conciencia" en la Obra de Manuel Manquilef, en Revista Chilena de Antropología 21: 59-80.

Manquilef, Manuel (1915). ¡Las Tierras de Arauco! El Último Cacique. Imprenta y Encuadernación "Modernista".

Marimán, José (2012). Autodeterminación. Ideas políticas mapuche en los albores del siglo XXI. LOM.

— (2007a). La Misión de Kepe. Conquista y Evangelización, en Menard, André y Pavez, Jorge. Mapuche y anglicanos. Vestigios fotográficos de la Misión Araucana de Kepe, 1986-1908. (pp 137-144). Ocho Libros Editores,

— (2007b). La Corporación Araucana (1946-1950): En el Quehacer del Diputado Venancio Coñuepán, Tesis para optar al grado de Magíster en Historia. Universidad de Chile, Facultad de Filosofía y Humanidades.

Menard, André y Pavez, Jorge (2005). El Congreso Araucano. Ley, Raza y escritura en la política mapuche, en Política 44: 211-232

Memmi, Albert (1986). Racismo y odio del Otro, en Correo de la Unesco: 14-15.

Menard, André y Pavez, Jorge (2007). Nombres, cuerpos y rostros mapuche. Presentación al álbum fotográfico de la Misión Araucana de Kepe, en Menard, André y Pavez, Jorge. Mapuche y anglicanos. Vestigios fotográficos de la Misión Araucana de Kepe, 1986-1908. (pp. 11-39). Ocho Libros Editores.

Mora, Héctor y Samaniego, Mario (editores) (2018). Los mapuche en la pluma de los araucanistas. Seis estudios sobre la construcción de la alteridad. Ocho libros editores. 
Nahuelpán, Héctor (2013). Formación colonial del Estado y desposesión en Ngulumapu, en VV.AA. Ta ĩ̃ Fijke xipa rakizuameluwün. Historia, colonialismo y resistencia desde el País Mapuche. (pp. 119-152). Ediciones Comunidad de Historia Mapuche.

Nahuelpan, Héctor y Antimil, Jaime (2019).Colonialismo republicano, violencia y subordinación racial mapuche en Chile durante el siglo XX", en HiSTOReLo. Revista de Historia Regional y Local 21(11): 211-248.

Nahuelpán, Héctor y Marimán, Pablo (2009). Pueblo Mapuche y educación superior: ¿Inclusión, interculturalidad y/o autonomía?, En Revista ISEES: Inclusión Social y Equidad en la Educación Superior 4: 83-102.

Omi, Michael y Winant, Howard (1994). Racial formation, en Omi, Michael y Winant, Howard Racial formation in the United States. From the 1960s to the 1990s. (pp. 53-76). Routledge.

Pavez, Jorge (2015). Laboratorios etnográficos. Los archivos de la antropología en Chile (1880-1980). Ediciones Universidad Alberto Hurtado.

Pichilaf, Norberto (febrero de 1943). No somos de los años de la conquista. Heraldo Araucano, número 3, año III.

Porma, Juan (2015). Violencia colonial en la escuela: el caso de la comunidad José Porma en el siglo XX, en Antileo, Enrique; Huinca, Herson; Cárcamo-Huechante, Luis y Calfío, Margarita. Awükan ka kuxankan zugu Wajmapu mew. Violencias Coloniales en Wajmapu. (pp. 189-206). Ediciones Comunidad de Historia Mapuche.

Quijano, Aníbal (2000). Colonialidad del poder y clasificación social, en Journal of World System Research: 342-386.

Ramay, Allison y Loncón, Elisa (2016). Constuyendo el valor cultural: Jimnasia Nacional (1914) de Manuel Manquilef y la educación intercultural en Chile, en Alpha 42 Osorno: 273-284.

Sarzuri-Lima, Marcelo (2013). ¿Violencias legítimas? Violencia, educación y escuela. Revista Integra Educativa 6 (2): 7-10.

Vergara, Jorge Iván y Gundermann, Hans (2016). Chile y el Instituto Indigenista Interamericano 1940-1993. Una visión de conjunto, en Chungara, Revista de Antropología Chilena 48(1):127-144

Vergara, Jorge Iván; Foerster, Rolf y Gundermann, Hans (2005). Instituciones mediadoras, legislación y movimiento indígena de Dasin a Conadi (1953-1994), en Atenea 491:71-85.

Wallerstein, Immanuel y Balibar, Etienne (1991). Raza, nación y clase. IAPELA. (obra original de 1988).

Wieviorka, Michel (2009). El racismo: una introducción. Gedisa.

Williams, Eric (2011). Capitalismo y esclavitud. Traficantes de sueños. (obra original de 1944). 